\title{
MONITORING OF THE PETROGENICALLY POLLUTED TERRITORIES
}

\author{
S.R. Hajiyeva, E.M. Gadirova* \\ Baku State University, Baku, Azerbaijan \\ *elmina2010@mail.ru
}

\begin{abstract}
Environmental monitoring has been carried out in the regions of Azerbaijan, chemical analysis of crude oils taken from Siyazan and May 28 has been counducted, and the degree of oil contamination of these areas has been determined. At the same time, the offshore waters of Mardakan and Gunashli regions have been taken and organic toxic substances have been identified in its content with the help of chromatographic analysis.
\end{abstract}

Key words: PAH, chemical analysis, gas chromatography, monitoring, water samples.

\section{Introduction:}

Aromatic compounds enter the biosphere in various ways and their sources are industrial enterprises, transport, and household waste. The particular attention given to aromatic compounds is largely due to their carcinogenic properties. Polycyclic aromatic hydrocarbons (PAHs) enter the atmosphere as a result of emissions and wastes from coke plants, some chemical plants, exhaust from internal combustion engines, and combustion products of various fuels. Groundwater is often contaminated with PAHs due to various wastewater sludge.

Aromatic hydrocarbons in petroleum range from 5 to $55 \%$. These are the most toxic components of oil, and at a concentration of only $1 \%$ in water, they kill aquatic lower plants. Oil, containing 38\% of aromatic hydrocarbons, significantly inhibits the growth of higher plants, and with an increase in the aromaticity of oil, their herbicidal activity increases. The content of all groups of polycyclic aromatic hydrocarbons gradually decreases with the gradual transformation of oil in the soil.

Polycyclic aromatic hydrocarbons (PAH) formed during fuel combustion are a multicomponent mixture, the individual analysis of each component of which is difficult without preliminary preparation of the sample for analysis. After preliminary chromatography of the sample by the method of column chromatography in a thin layer or by the method of differential sublimation, it is possible to analyze individual PAH using UV spectroscopy. The method allows to determine the concentration of various PAH in air up to $10-5 \%$, or $0.1 \mu \mathrm{g} / \mathrm{ml}$ in solution [1-3].

Organic compounds such as polycyclic aromatic hydrocarbons (PAH) are a global environmental concern as they cause inflammation and skin cancer. As you know, there are two types of anthropogenic sources of hydrocarbons: petrogenic and pyrogenic sources. 
Petrogenic sources include crude oil and petroleum-derived hydrocarbon compounds. Pyrogenic sources of hydrocarbon compounds are formed as a result of incomplete combustion of organic substances such as oil, wood, coal, etc. [4,5]. About 6.1 million tons of oil products are thrown into the ocean every year, most of which are of anthropogenic origin. Before entering the open sea, these oil products pass through the entire coastal zone.

The Caspian Sea is a very sensitive ecosystem. Over the past decades, under the influence of anthropogenic and biochemical factors, the state of ecosystems in general has deteriorated sharply, and especially in the northeastern part of the sea. Observations of recent years show that the waters of the Caspian Sea, especially along the coast of the National Park, are also polluted by oil and sewage [4,5]. Industrialization and urbanization in the Caspian region has been developing rapidly over the past several decades and the associated increase in hydrocarbons is a concern in the region. Offshore production and accidental oil spills, industrial waste, wastewater, discharges flowing down from river water are considered the main source of anthropogenic hydrocarbons in the marine environment [6-8]. Industry is believed to be the main source of oil pollution in the Caspian Sea. The total amount of industrial waste discharged into the Caspian Sea averages 2342.0 million $\mathrm{m} 3$ per year. Such waters contain 122.5 thousand tons of oil, 1.1 thousand tons of phenols, 9.9 thousand tons of organic chemistry products. The total content of hydrocarbons in the North-Western part of the South Caspian was small - 32-54.2 $\mu \mathrm{g} / \mathrm{g}$. In this area, in the vicinity of oil fields, the concentration of phenols was $0.002-0.003 \mu \mathrm{g} / \mathrm{g}[9,10]$. Pollution of water and bottom sediments is noted throughout the Absheron Peninsula and in the Baku Bay. The main volume of pollution ( $90 \%$ of the total) enters the Caspiaan Sea with river runoff $[11,12]$.

In the reviewed article, we also analyzed wastewater taken from the territories of Mardakan and Hovsan. It was important for us to calculate the amount of PAHs in these polluted waters. After purification, these waters are discharged into the Caspian Sea, and even in small quantities these harmful substances are dangerous for the flora and fauna of the sea and the environment. As is already known, PAHs are very dangerous for the environment, for living organisms in aquatic ecosystems, and therefore, the identification of hazardous substances and the application of methods for their destruction is very important $[13,14]$.

\section{Experimental part:}

Crude oil were extracted from two regions of Azerbaijan - Siyazan , 28 May and their chromatographic analysis was carried out. At the same time, water samples has been taken for analysis from the two sites: Mardakan and Hovsan coasts at depths of $0.5 \mathrm{~m}$ from the sea level with the "12 L Niskin" sampler. Quality analysis of crude oils were carried out with A flame-ionizing GC equipped with ZB-1 (Phenomenex, USA) -FID 6890 (Agilent, USA) gas chromatographic detector. In the analysis, helium was used as a gas-bearing agent.

Chromatographic analysis of oil from two regions of Azerbaijan (Siyazan and May 28) was carried out. The determination of the chemical analysis of these oils, as well as the determination of organic toxic substances in offshore waters from Mardakan and Hovsan fields was implemented with the support of the Caspian Ecology Laboratory(Azerbaijan).

\section{Explantion of the results:}

The chemical analysis of crude oil gives us a reason to say that the sulfur content in our local oil ranges from 0.2 to $0.3 \%$. This is not a big indicator, and this is one of the superior 
features of our oil. However, the little amount of sulfur content of the oil has environmental problems $[15,16]$. Car engines working with such oil fractions produce sulfuric gases into the environment by contaminating the atmosphere, causing greenhouse effect[17]. Therefore, even the least sulfur content is not satisfactory. There are various methods to reduce sulfur content in the oil.The gas chromatographic analysis of crude oil from the three regions of Azerbaijan is shown below (Figure 1-2).

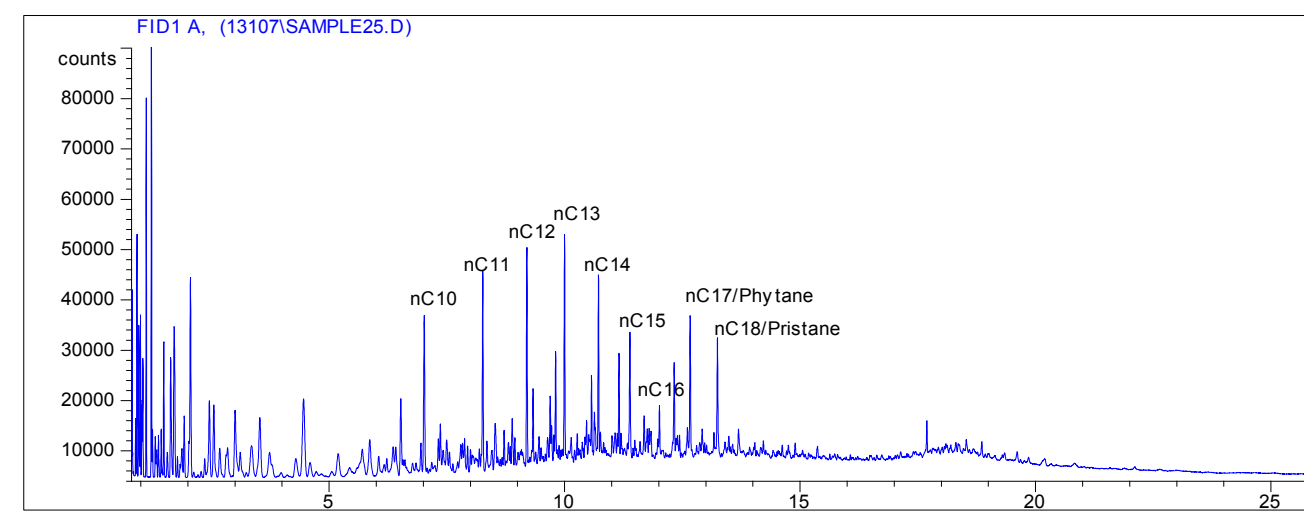

Figure 1. Gas chromatographic analysis of 28 May oil

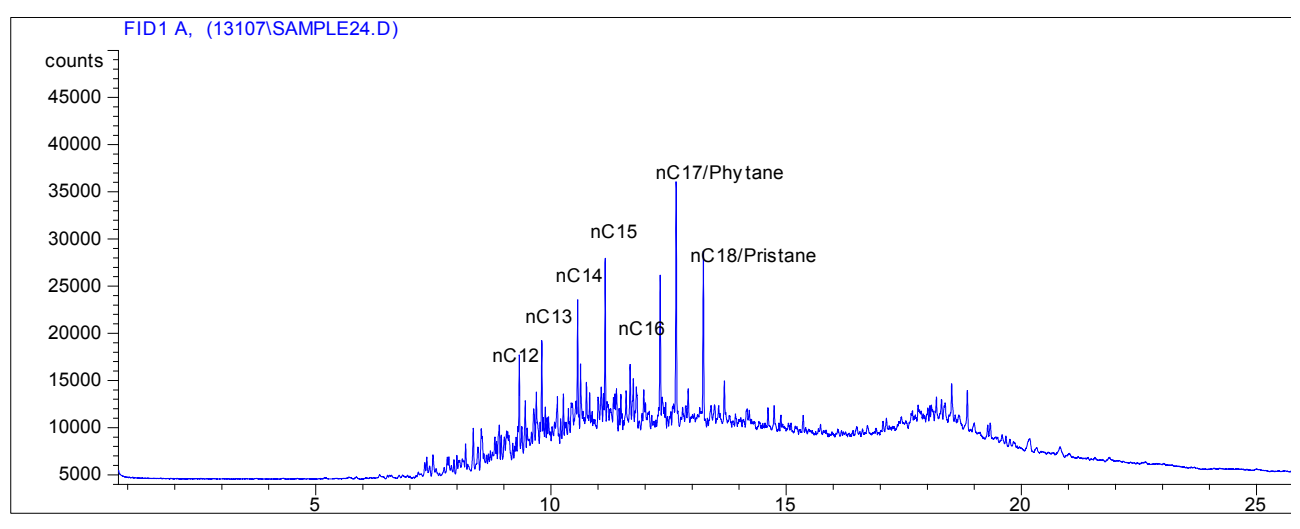

Figure 2. Gas chromatographic analysis of Siyazan oil

Although the composition of crude oil mainly consists of alkanes and naphthenes, mainly composed of $\mathrm{C}_{10}-\mathrm{C}_{16}$ alkanes, aromatic hydrocarbons are formed as a result of transformation processes in the content of oil. The presence of salt over norm in the analysis of seawater and the nearness of the $\mathrm{pH}$ to the alkaline environment suggests that their composition is contaminated with organic and inorganic compounds[18-20]. At the same time, the content of water contaminated with oil and oil products has been determined by us, and analysis has been carried out to establish the toxic components from organic origin. For this purpose, water samples from the two parts of the Absheron peninsula: from the Mardakan and the Caspian Sea near Hovsan were taken. As a result of this water analyzes, the content of these organic substances has been clarified and chromatographic analysis is done, and the results are given in table 1 and figure 3-4. 
Table 1. Organic content of water samples taken from Mardakan and Hovsan areas

\begin{tabular}{|l|l|l|}
\hline \multicolumn{1}{|c|}{$\begin{array}{c}\text { Polysilic aromatic hydrocarbons } \\
\boldsymbol{\mu g} / \mathbf{l}\end{array}$} & Mardakan & Hovsan \\
\hline Naphthalene & 0,09 & 0,19 \\
\hline Achenthylene & $<0.01$ & $<0.01$ \\
\hline Acenaften & 0,01 & 0,01 \\
\hline Fluoren & 0,04 & 0,07 \\
\hline Fenantren & 0,09 & 0,17 \\
\hline Anthracene & 0,01 & 0,01 \\
\hline Fluoranten & 0,01 & 0,01 \\
\hline Piren & 0,01 & 0,01 \\
\hline Benz (a) anthracene & $<0.01$ & 0,00 \\
\hline The chrezen & 0,02 & 0,01 \\
\hline Benz (b + j + k) fluorantene & 0,01 & 0,03 \\
\hline Benz (a) pyrene & 0,01 & 0,01 \\
\hline Inden (1,2,3-cd) pyrene & $<0.01$ & $<0.01$ \\
\hline Benz (ghi) perilen & $<0.01$ & 0,53 \\
\hline Dibenz (ah) antracen & 0,29 & \\
\hline$\Sigma$ 16 Individual PAC & & \\
\hline
\end{tabular}

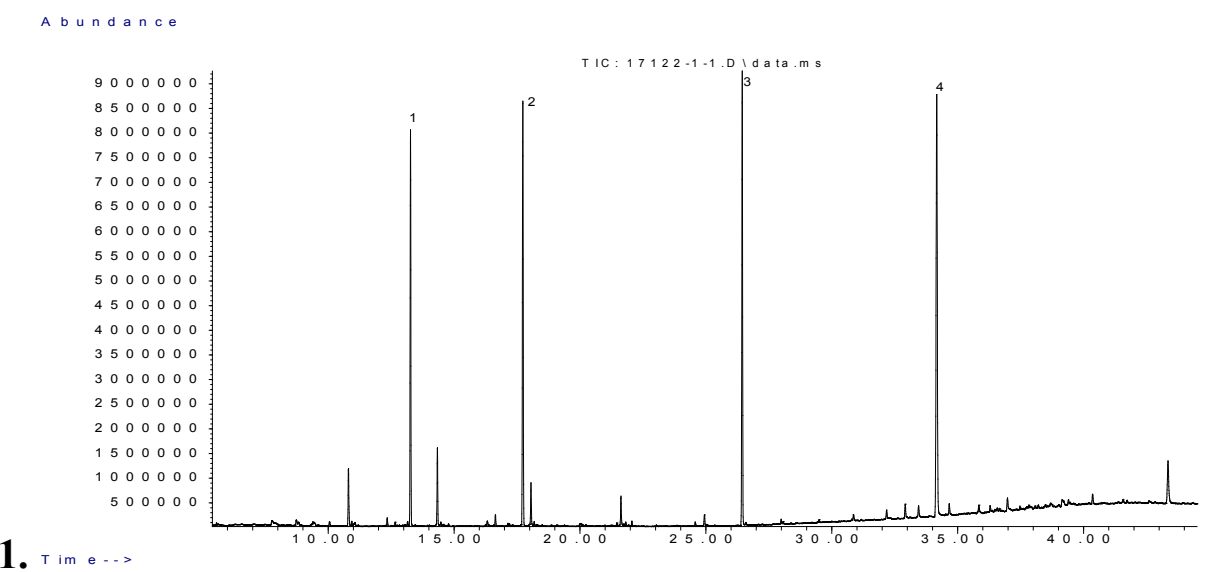

Figure 3. Chromatographic analysis of water samples taken from Mardakan field 


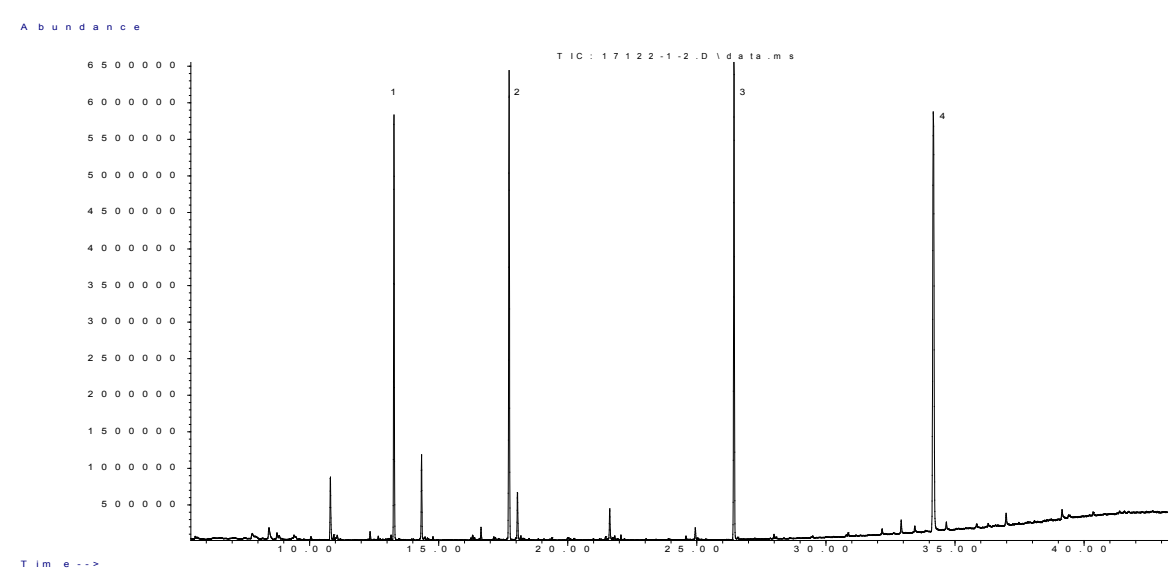

Figure 4. Chromatographic analysis of water samples from Hovsan field

\section{Result and Conclusion:}

According to the results of monitoring, pollution of oil products was observed in the southern part of the Caspian Sea. In this case, pollution of the soil, in particular contamination of water basins with oil and petroleum products is unwelcome, because the phenolic compounds have a high permissible concentration in the food products related to water (such as fish) and soil content (vegetable crops), which are ecologically useless, and ultimately lead to unwanted malignant tumors for the human body. More pollution of the Hovsan area was observed. The purpose of environmental monitoring was to expose these qualities. The continuation of these monitoring in the future will be the main subject of our research.

\section{References:}

1. A. S. Stepanovsky.General ecology: Textbook. Ed. // M.UNITI, 2000, 510 p.

2.Korshenko A., Gul A.G. Pollution of the Caspian Sea.// Hdb. Env. Chem. Vol. 5. Part P. Springer-Verlag, 2005.p.105-142.

3. Novikov Yu.V. Ecology of the environment and human: Moscow. 2005, p. 347.

4. Hajiyeva S.R., Gadirova E.M., etc. Methods for cleaning water contaminated with oil // Azerbaijan Chemistry Journal Baku, 2014, No. 1, p. 35-38.

5. Caspian Sea. State of the Environment // Report of the Interim Secretariat of the Framework Convention for the Protection of the Marine Environment of the Caspian Sea and the Bureau for Management and Coordination of the CASPECO Project. 2011, p.28.

6. Ostroumov S.A. Problems of ecological safety of water supply sources. 2006, No. 5, p. 17-20.

7. Neff J. M. Bioaccumulation in Marine Organisms. Amsterdam, Elsevier, 2002, 460 p.

8.Yunker M. B., Macdonald R. W., Vingarzan R. et al. PAH in the Fraser River basin: a critical appraisal of PAH ratios as indicators of PAH source and composition //Organic Geochemistry. 2002, vol. 33, p. 489-515.

9. Bogdanovski G.A. Chemical ecology // Moscow: Moscow State University. 1994. 237 p. 
10. Problems of ecological safety of water sources. Ecological systems and appliances.2006,N 5. p.17-20.

11. Kostianoy Ed. A.,Kosarev A.,Korshenko A.,Gul A.G.The Caspian Sea Environment Vol. 5 Water Pollution Pollution of the Caspian Sea. Hdb. Env. Chem.V. 5. Part P, Springer-Verlag,2005, p.109-142.

12. Abdul Kasymov.Ecology of the Caspian Sea plankton, Baku,2004,p. 19-20.

13. Korshenko A.,Gul A.G. Pollution of the Caspian Sea. Hdb. Env. Chem.V. 5. Part P, Springer-Verlag,2005,p.109-142.

14.S.R.Hajiyeva,E.M.Gadirova. Advances in Biology\&Earth Sciences. Baku, 2018, vol.3.No.3. p.248-256.

15. S.N. Gosling, N.W. Arnell. A global assessment of the impact of climate change on water scarcity. Clim. Change 134,2016,p.371-385.

16. S. Mohammadi, A. Kargari, H. Sanaeepur, K. Abbassian, A. Najafi, E. Mofarrah.Phenol removal from industrial waste-waters: a short review. Desalin. Water Treat.2015, 53, p.2215-2234

17. S.R.Hajieva,E.M.Gadirova,N.Sh. Sharifova,etc. Published under licence by IOP Publishing Ltd IOP Conference Series: Materials Science and Engineering, 2019,vol.570, N\#1. https://iopscience.iop.org/article/10.1088/1757-899X/570/1/012031

18. Shmal A.G. Environmental safety factors-environmental risks. Publisher: Bronnitsy, MP "ICC BNTV, 2010,192p.

19. KorobkinV.I.,Korobkin L.V.:Peredelsky- Rostov: Ecology, 2003,576 p.

20. Khoruzhaya T.A. Assessment of environmental hazard: "Book service", 2002, 208 p. 